\title{
Effect of Flecainide on Regional Left Ventricular Wall Motion After Acute Intravenous, Acute Oral and Chronic Oral Administration Late After Coronary Artery Bypass Grafting
}

\author{
GUIDO L.J. VANHALEWEYK, MD, HARALD J. TEN KATEN, MSC, \\ RONALD W. BROWER, PhD, and PATRICK W. SERRUYS, MD
}

Epicardial marker motion was measured in 14 patients before flecainide administration, immediately after an intravenous dose of $2 \mathrm{mg} / \mathrm{kg}$ over $15 \mathrm{~min}$ utes (maximum $150 \mathrm{mg}$ ) and 15 minutes thereafter. Platinum epicardial markers had been implanted more than $\mathbf{4}$ years earlier at the time of coronary artery bypass grafting. Maximal and minimal marker separation (Lmax and Lmin) during the cardiac cycle were measured and regional shortening fraction (Lmax - Lmin)/Lmax) was determined as a percentage. After intravenous flecainide, a significant increase in end-diastolic (immediately after $2.8 \%$; after 15 minutes $2.1 \%)$ and end-systolic $(3.6 \%$ and $3.2 \%$ ) regional dimensions was observed, together with a decrease in regional myocardial shortening $(9.3 \%$ and $9.0 \%)$. One week later, after a single oral dose of $200 \mathrm{mg}$ of flecainide, Lmax and Lmin had increased $2.4 \%$ and $2.7 \%$, while region- al myocardial shortening did not differ significantly from baseline values. In 10 patients measurements were repeated after 6 weeks of chronic oral treatment with $300 \mathrm{mg} /$ day. Despite plasma flecainide levels similar to those after intravenous administration, no significant changes in end-diastolic and end-systolic dimensions or regional shortening fraction were observed. Thus, acute intravenous or oral flecainide administration increases regional end-diastolic and end-systolic dimensions, but only intravenous administration decreases regional shortening fraction. Values during chronic administration indicate that regional myocardial function is more affected at the time of rising or acutely changing flecainide plasma levels than when stable plasma levels are achieved.

(Am J Cardiol 1986;58:470-475)
F slows atrial, nodal and ventricular conduction and increases atrial and ventricular refractoriness, ${ }^{1-4}$ is effective in suppressing ventricular arrhythmias and reentrant tachycardias related to anomalous atrioventricular pathways. ${ }^{4-12}$

A myocardial depressant effect after intravenous administration of flecainide in humans has been reported, ${ }^{13-15}$ whereas echocardiographic measures of

From the Thoraxcenter, University Hospital "Dijkzigt," Rotterdam, 'l'he Netherlands. Manuscript received May 21, 1985; revised manuscript received May 14, 1986, accepted May 16, 1986.

Address for reprints: Patrick W. Serruys, MD, Catheterization Laboratory, Thoraxcenter, University Hospital "Dijkzigt," Dr. Molewaterplein 40, 3015 GD Rotterdam, The Netherlands. left ventricular function measured during oral treatment usually did not change..$^{5-7,16}$ However, clinical heart failure during chronic oral treatment has been reported to develop or to become aggravated in approximately $4 \%$ of patients. ${ }^{15}$

We evaluated the effect of acute intravenous, acute oral and chronic oral flecainide administration on left ventricular regional wall motion, as measured from implanted epicardial markers, in the same patients with coronary artery disease who had previously undergone coronary artery bypass surgery (CABG). ${ }^{17}$

\section{Methods}

Fourteen men, aged 50 to 63 years (mean 55), participated in the study. All had undergone CABG 4 to 7 years earlier. Five patients presented with chronic 
TABLE I Patients

\begin{tabular}{rcccccccc}
\hline & & & & & & & \multicolumn{2}{c}{ Marker Pairs } \\
\cline { 7 - 8 } Pt & Age (yr) & Previous Ml & AP & NYHA & EDV $\left(\mathrm{ml} / \mathrm{m}^{2}\right)$ & $\begin{array}{c}\text { EF } \\
(\%)\end{array}$ & Hypokinetic & Normokinetic \\
\hline 1 & 54 & + & + & 2 & 62 & 68 & 2 & 1 \\
2 & 53 & - & - & 1 & 85 & 64 & 1 & 1 \\
3 & 62 & + & + & 2 & 68 & 65 & 1 & 1 \\
4 & 63 & + & + & 2 & 54 & 74 & 1 & 2 \\
5 & 52 & + & + & 2 & 120 & 30 & 2 & 1 \\
6 & 60 & + & - & 2 & 83 & 39 & 1 & 2 \\
7 & 51 & - & - & 1 & 79 & 56 & 1 & 1 \\
8 & 51 & + & - & 1 & 64 & - & 0 & 1 \\
9 & 62 & + & - & 1 & 115 & 32 & 3 & 0 \\
10 & 57 & + & + & 2 & 78 & 49 & 1 & 1 \\
11 & 50 & + & + & 1 & 67 & 64 & 1 & 1 \\
12 & 52 & + & - & 1 & 113 & 56 & 1 & 1 \\
13 & 53 & + & - & 1 & 74 & 64 & 1 & 2 \\
14 & 56 & + & - & 1 & 98 & 46 & 1 & 2 \\
\end{tabular}

$\mathrm{AP}=$ angina pectoris; $\mathrm{EDV}=$ end-diastolic volume; $\mathrm{EF}=$ ejection fraction; $\mathrm{MI}=$ myocardial infarction; $\mathrm{NYHA}=$ New York Heart Association class.

ventricular arrhythmias and 9 had no significant ventricular arrhythmias. All gave informed consent to participate in this study. At the time of CABG 12 patients had 3-vessel and 2 had 2-vessel coronary artery disease (Table I).

A complete medical history as well as a routine physical examination were obtained from all patients on entering the study.

Heart rate, blood pressure, biplane x-ray cinefilm of radiopaque marker motion, electrocardiographic intervals and plasma flecainide levels were measured. These variables were measured with the patient in the supine position in the catheterization laboratory and were repeated 6 times. During the first visit, indwelling intravenous catheters were inserted at least half an hour before values were measured. After baseline measurements were made, flecainide was administered intravenously over 15 minutes at a dose of 2 $\mathrm{mg} / \mathrm{kg}$ (maximum $150 \mathrm{mg}$ ). Measurements were repeated immediately thereafter and 15 minutes later; blood samples were obtained at the same times. One week later, measurements were taken 2 to 4 hours (mean 2 hours 55 minutes) after an oral flecainide dose of $200 \mathrm{mg}$. Thereafter, flecainide, $150 \mathrm{mg} 2$ times daily, was administered during a 6 -week period. Ten patients participated in this chronic treatment period. At the end of this period the measurements were repeated 6 to 10 hours (mean 8 hours 20 minutes) after the last oral dose. Flecainide therapy was then discontinued and final measurements were recorded 1 week thereafter.

Plasma flecainide levels were determined using a gas-liquid chromatographic method; measurements were conducted at the Department of Pharmacology of the University of Groningen.

Regional wall motion: Regional myocardial motion was determined from radiopaque markers implanted during $\mathrm{CABG}$ on the left ventricular epicardium in each bypassed region in pairs approximately $2 \mathrm{~cm}$ apart and located 0 to $3 \mathrm{~cm}$ distal to the coronary anastomosis (Fig. 1). This technique has been described previously. ${ }^{17-21}$ Three consccutive beats worc recorded on synchronized biplane cinefilms ( 50 frames/s) in $30^{\circ}$ right anterior oblique and $60^{\circ}$ left anterior oblique projections. Correction for x-ray and optical distortion was performed to give true anatomic dimensions. Because the biplane technique was used, small errors due to lateral and transverse rotation were eliminated. The position of the roentgen apparatus was not changed during sequential recordings. Separation of marker pairs was plotted with regard to the onset of electrical activity. Lmax and Lmin were defined as maximal and minimal marker separation. The shortening fraction between these 2 points was calculated as (Lmax - Lmin)/Lmax and was expressed as a percentage.

Because marker filming at each measurement was performed without repositioning the equipment or the patient, the measurement error is primarily due to beat-to-beat variability, which is defined as the pooled slandard deviation in Lmax divided by Lmax and expressed as a percentage. For biplane recording this averaged $0.66 \%$. Given a marker separation of $2 \mathrm{~cm}$ and averaging the results of 3 beats, the $95 \%$ confidence limit of the mean is less than $0.13 \mathrm{~mm}$. Measurement error and observer variability have been reported. ${ }^{17}$

Regional myocardial shortening was considered normal if it was more than $10 \%$, hypokinetic if between 5 and $10 \%$ and akinetic if less than $5 \% .{ }^{17}$

\section{Results}

Acute intravenous administration: Measurements were performed in 14 patients with 34 platinum marker pairs implanted. A mean flecainide dose of $139.6 \mathrm{mg}$ (range 120 to 150) was administered intravenously over 15 minutes. Except for slight buccal paresthesias in 1 patient, no adverse effects occurred. No significant changes in heart rate or blood pressure were seen. Plasma flecainide levels immediately after infusion and 15 minutes later were $541 \pm 157$ and $285 \pm 62 \mathrm{ng} /$ $\mathrm{ml}$, respectively $(\mathrm{n}=12$ ). 
TABLE II Regional Left Ventricular Wall Motion Measurements After Intravenous and Oral Flecainide

\begin{tabular}{|c|c|c|c|c|c|c|c|}
\hline & Control & $\begin{array}{l}\text { After } \\
\text { i.v. FI. }\end{array}$ & p Value* & $\begin{array}{l}15 \text { Min. After } \\
\text { i.v. FI. }\end{array}$ & p Value* & After Oral FI. & p Value* \\
\hline$L \max (\mathrm{cm})$ & $2.86 \pm 0.98$ & $2.94 \pm 0.99$ & 0.011 & $2.92 \pm 0.97$ & 0.031 & $2.93 \pm 0.98$ & 0.029 \\
\hline $\operatorname{Lmin}(\mathrm{cm})$ & $2.53 \pm 0.90$ & $2.62 \pm 0.91$ & 0.0007 & $2.61 \pm 0.89$ & 0.0025 & $2.60 \pm 0.88$ & 0.012 \\
\hline SF $(\%)(n=34)$ & $11.74 \pm 4.89$ & $10.65 \pm 4.32$ & 0.0019 & $10.68 \pm 4.59$ & 0.0002 & $11.09 \pm 4.68$ & NS \\
\hline $\begin{array}{r}\text { SF hypokinetic + akinetic } \\
\text { segments }(\%)(n=17)\end{array}$ & $7.74 \pm 1.92$ & $7.29 \pm 2.50$ & NS & $7.07 \pm 2.34$ & NS & $7.46 \pm 2.84$ & NS \\
\hline $\begin{array}{l}\text { SF normokinetic } \\
\quad \text { segments }(\%)(n=17)\end{array}$ & $15.75 \pm 3.47$ & $14.01 \pm 2.89$ & 0.0013 & $14.31 \pm 3.18$ & 0.0006 & $14.72 \pm 3.02$ & NS \\
\hline
\end{tabular}

* Student paired $t$ test with regard to control.

FI. = flecainide; NS = not significant; SF = shortening fraction.

Electrocardiographic intervals: PR interval, QRS duration and QT interval increased significantly, by $24 \%, 23 \%$ and $8 \%$, after flecainide infusion. These intervals remained prolonged by $19 \%, 15 \%$ and $7 \% 15$ minutes later $(\mathrm{p}<0.05$ ).

Hcart rate before, immediately after and $15 \mathrm{~min}$ utes later was 70,71 and 70 beats/min (difference not significant).

Regional wall motion: Both Lmax and Lmin increased significantly after intravenous flecainide administration (Table II).

Shortening fraction decreased significantly, since the increase in Lmin was more pronounced than the increase in Lmax. Shortening fraction was $11.74 \pm$ $4.89 \%$ before flecainide and decreased to $10.65 \pm$ $4.32 \%$ after infusion and $10.68 \pm 4.59 \% 15$ minutes later (Table II).

Regional myocardial wall motion was normokinetic in 17 segments, hypokinetic in 16 and akinetic in 1 segment (Table I). A significant decrease in shortening fraction was observed after flecainide in normokinetic segments but not in hypokinetic segments (Table II).

Oral administration: After a single oral dose of 200 mg: Plasma flecainide level determined 2 to 4 hours (mean 2 hours 55 minutes) after a single oral dose of $200 \mathrm{mg}$ was $262 \pm 73 \mathrm{ng} / \mathrm{ml}(\mathrm{n}=12)$. This level was significantly lower than that immediately after intravenous infusion of flecainide, but not different from the level 15 minutes after intravenous infusion. QRS interval did not differ from the baseline level, whereas PR and QT intervals increased by $11 \%$ and $5 \%$, respectively ( $\mathrm{p}<0.05$ ).

Regional wall motion: Lmax and Lmin were $2.93 \pm$ 0.98 and $2.60 \pm 0.88 \mathrm{~cm}$. Both values were significantly different from baseline values. Shortening fraction was $11.09 \pm 4.68 \%$, not significantly different from the baseline value (Table II).

Lmax after a single oral dose did not differ from Lmax after intravenous administration of flecainide, whereas the increase in Lmin after oral flecainide

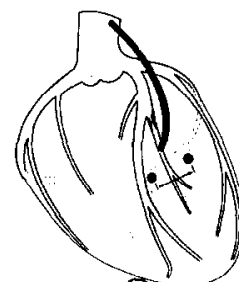

(a)

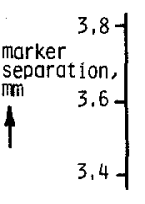

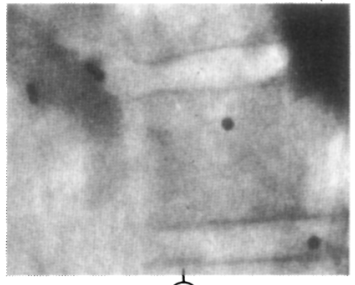

(b)

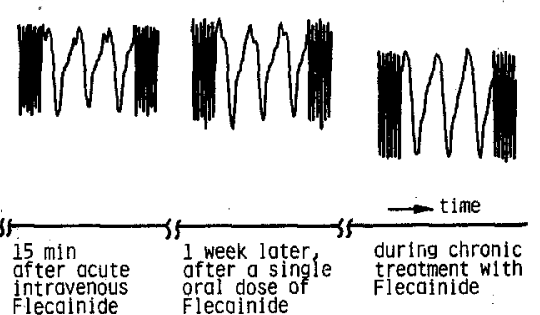

FIGURE 1. a, regional myocardial shortening was determined from radiopaque markers implanted during surgery on the left ventricular epicardium in each bypassed region, in pairs $2 \mathrm{~cm}$ apart and located from 0 to $3 \mathrm{~cm}$ distal to the coronary anastomosis. ${ }^{17} \mathrm{~b}$, cineradiogram of 1 marker pair of bars and 1 marker pair of beads in $60^{\circ}$ left anterior oblique projection. c, marker pair shortening for a normal contraction. Separation of the marker pair is plotted with regard to the onset of electrical activity (Q wave of the electrocardiogram [ECG]). Shortening fraction (SF) is determined beat by beat and averaged over 3 beats. Lmax and Lmin = maximal and minimal marker separation. $d$, motion pattern of 1 marker pair in 1 patient during 3 consecutive beats before flecainide infusion, immediately after Infusion, 15 minutes after infusion, after a single oral dose and during chronic treatment. After infusion of flecainide and after a single oral dose Lmax and Lmin increase. This increase is less during chronic treatment. Calculated shortening fraction before flecainide was $8.15 \%$, immedlately after and 15 minutes after intravenous infusion $6.14 \%$ and $6.31 \%$ respectively, after a single oral dose $7.53 \%$ and during chronic treatment $8.09 \%$. 
tended to be less pronounced than after intravenous administration $(\mathrm{p}=0.06)$.

During chronic oral treatment: Measurements dur* ing chronic oral treatment with $300 \mathrm{mg} /$ day of flecainide were available in 10 patients with 26 marker pairs implanted. One patient stopped therapy because of gastrointestinal complaints. Another patient was withdrawn from the study after an episode of unexplained syncope; the plasma flecainide level shortly thereafter was $350 \mathrm{ng} / \mathrm{ml}$. On the electrocardiogram first-degree atrioventricular block was present without significant ventricular arrhythmias. The patient was readmitted a few months later to the neurologic department because of amaurosis fugax, and right carotid artery stenosis was diagnosed. Two patients refused chronic administration of the drug. The plasma flecainide level during chronic treatment determined 6 to 10 hours after the last flecainide dose (mean 8 hours 20 minutes) was $449 \pm 132 \mathrm{ng} / \mathrm{ml}(\mathrm{n}=10)$. This level was higher than that after a single oral dose $(p<0.005)$ and 15 minutes after intravenous infusion $(p<0.01)$, but was not significantly different from the level immediately after intravenous infusion.

During chronic flecainide administration QRS duration and QT interval were not significantly different from baseline values, whereas PR interval increased by $12 \%$ ( $\mathrm{p}<0.05)$.

Regional wall motion: Lmax and Lmin were $2.93 \pm$ 1.05 and $2.58 \pm 0.95 \mathrm{~cm}$, respectively. Neither value was significantly different from baseline $[2.89 \pm 1.08$ and $2.53 \pm 0.99 \mathrm{~cm}, \mathrm{n}=26$ ). Shortening fraction was $12.0 \pm 4.7 \%$ (baseline $12.5 \pm 4.8 \%, \mathrm{p}<0.2$ ) and remained unchanged.

Lmax and Lmin were significantly smaller during chronic treatment than after intravenous injection or after a single oral flecainide dose. Shortening fraction during chronic treatment was significantly greater than immediately after an intravenous dose of flecainide $(12.0 \pm 4.7 \%$ vs $11.2 \pm 4.0 \%, p<0.01)$ (Fig. 2).

\section{Discussion}

Regional myocardial function, particularly in patients with coronary artery disease, has been assessed by 2-dimensional and M-mode echocardiography, by radiopaque contrast and by radionuclide ventriculography. The last technique was not considered for the present study because repeated measurements, and therefore repeated exposure to ionizing radiation, are required. None of these methods accurately assess transverse epicardial shortening. Our method provides accurate, specific and heretofore unavailable information on regional epicardial shortening and dimensions. ${ }^{17-21}$ We conservatively estimate that the overall margin of error is less than $0.66 \%$ in shortening fraction and less than $0.13 \mathrm{~mm}$ for a maximal marker separation (Lmax) of $20 \mathrm{~mm}$. In this study, we chose not to run a parallel control group because we showed in a previous study that measurements of regional epicardial shortening remain stable during a 6-month period in patients without intercurrent cardiac events. ${ }^{19}$ Therefore, we reasoned that each patient could serve as his own control. The clinical value of new antiar- rhythmic agents such as flecainide would be enhanced if there were only minimal depression of left ventricular function, so that patients with impaired cardiac function, who often present with severe ventricular arrhythmias, could also benefit. ${ }^{22}$

The hemodynamic effect of flecainide after acute intravenous administration has been studied previously, with similar results. ${ }^{13-15}$ Parameters related to myocardial contractility, such as peak positive $\mathrm{dP} / \mathrm{dt}$ and Vmax, decrease after intravenous administration of 2 $\mathrm{mg} / \mathrm{kg}$ of flecainide. ${ }^{14}$ Increases in pulmonary wedge pressure and left ventricular end-diastolic pressure have been observed, together with decreases in cardiac index ( 7 to $12 \%$ ) and left ventricular ejection fraction $(7 \text { to } 16 \%)^{13-15}$

The hemodynamic effects of acute and chronic oral administration of antiarrhythmic agents may be dissimilar from those observed during acute intravenous administration. In the present study we compared the effects of an acute oral dose of flecainide and of chronic flecainide administration with the effect of an intravenous dose in the same patients.

Immediately after intravenous administration both Lmax and Lmin increased and despite lower plasma flecainide levels, similar increases were observed 15 minutes later. In rats, cardiac tissue levels of flecainide have been reported to be 11- to 12-fold higher than plasma flecainide levels, but elimination kinetics from the heart are similar to plasma elimination kinetics. ${ }^{23}$ Cardiac tissue levels and elimination kinetics from the heart in humans are unknown. It might be hypothesized that flecainide elimination from the heart is slower in man, resulting in persistent hemodynamic

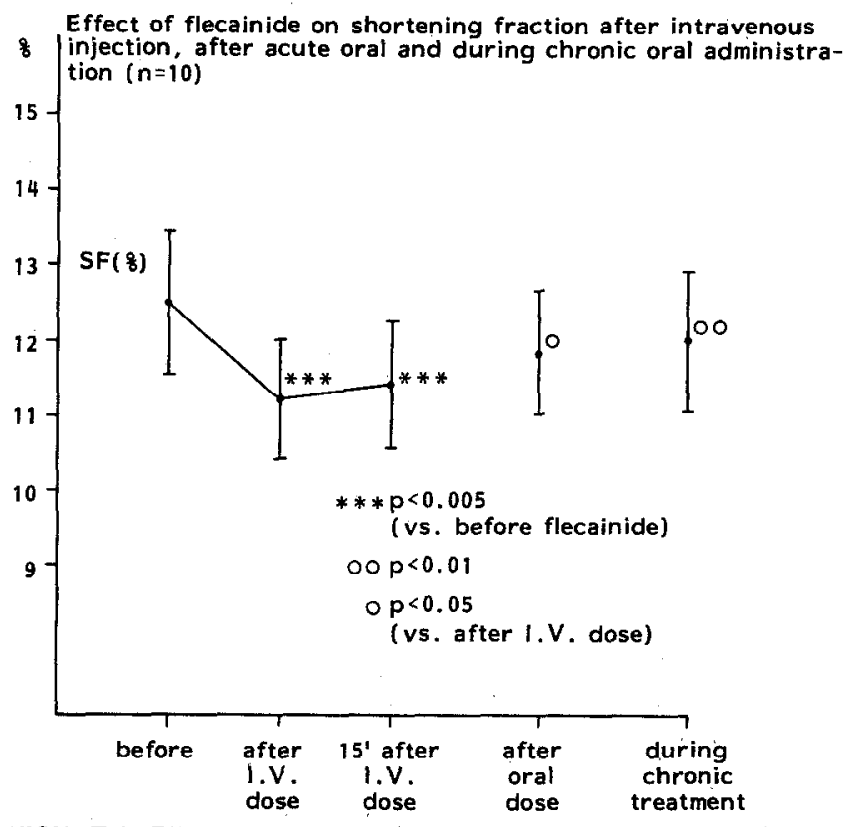

FIGURE 2. Effect of flecainide on regional wall shortening fraction (SF) in the 10 patients who received chronic treatment. The results after intravenous injection or acute oral administration in this large subgroup ( $n=10,26$ marker pairs) are similar to those of the whole group ( $n=14,34$ marker pairs). Values are mean \pm standard error of the mean. 
changes despite lower plasma flecainide levels. The present study shows an increase in systolic and diastolic regional dimensions after intravenous flecainide, and since the increase in end-systolic regional dimensions is more pronounced, a decrease in regional shortening fraction occurred. The changes may be related to the increase in end-systolic volume after flecainide administration observed by Legrand et al ${ }^{13}$ and the decrease in left ventricular ejection fraction observed by Legrand et a $1^{13}$ and Josephson et al..$^{15} \mathrm{We}$ have shown that regional myocardial shortening is not more impaired in hypokinetic segments than in normokinetic segments after intravenous flecainide administration.

During chronic oral flecainide treatment, investigators have evaluated echocardiographic measures of left ventricular function. No changes in ejection fraction and fractional shortening were observed. ${ }^{5-7}$ Hodges et $\mathrm{a}^{16}$ observed small increases in preejection period, preejection period/left ventricular ejection time ratio and left ventricular end-systolic volume, together with decreases in velocity of contractile shortening and left ventricular ejection fraction. That chronic flecainide administration can have a myocardial depressant effect is further emphasized by the observation ${ }^{15}$ that heart failure develops or was aggravated in $4 \%$ of 373 patients given flecainide to control ventricular tachyarrhythmias.

We measured regional wall motion after an oral dose of $200 \mathrm{mg}$ at the time of expected maximal blood plasma levels. ${ }^{24}$ We did see changes in systolic and diastolic regional dimensions after a single oral dose. Shortening fraction did not change significantly because both Lmax and Lmin increased in parallel, resulting in little net change of the quantity Lmax-Lmin. During chronic oral treatment with $300 \mathrm{mg} /$ day of flecainide 6 weeks after starting therapy, no significant changes in epicardial regional dimensions and shortening fraction were observed. Although the plasma flecainide level was not significantly different from that immediately after intravenous infusion, systolic regional dimensions were smaller and shortening fraction during chronic treatment was significantly higher. Despite higher plasma levels, regional dimensions were smaller during chronic oral treatment than after a single oral dose. These findings indicate that regional myocardial function appears to be more affected at the time of rising or acutely changing plasma flecainide levels than when stabilized plasma levels are achieved.

Some investigators have reported a slight increase in systemic vascular resistance after intravenous flecainide. ${ }^{13,14}$ As a consequence, an impaired emptying of the heart could be expected, attended by an increase in end-systolic and end-diastolic dimensions. We did not invasively measure systemic vascular resistance; however, systemic blood pressure did not change significantly. The increase in end-systolic and end-diastolic dimensions after intravenous administration and after a single oral dose can best be explained by a direct negative inotropic effect of flecai- nide, as shown in both experimental and human clinical studies. ${ }^{13-16}$

Regional myocardial shortening decreases after intravenous flecainide administration but appears not to be more impaired in hypokinetic than in normokinetic wall segments. Furthermore, during chronic administration and despite similar plasma flecaínide levels, the cffect on regional wall motion is less pronounced than after intravenous administration.

In conclusion, flecainide produces a negative inotropic effect in humans that prohibits its use in patients with severe heart failure; but it is not so great an effect to present serious problems in patients with a merely subnormal function.

Acknowledgment: We gratefully acknowledge the assistance of $\mathrm{H}$. Wolf; the technical staff of the catheterization laboratory; Y. te Giffel and N. Speelman, who patiently typed the manuscript; and W.H. van Gilst, who determined plasma flecainide levels.

\section{References}

1. Seipel L, Abendroth RR, Breithardt G. Elektrophysiologische Effekte des neuen Antiarrhythmikums Flecainid (R-818) beim Menschen. Z Kardiol 1981;70:524-529.

2. Vik-Mo H, Ohm Ole-Jorgen, Lund-Johansen P. Electrophysiologic effects of flecainide acetate in patients with sinus nodal dysfunction. Am I Cardiol 1982;50:1090-1094.

3. Olsson SB, Edvardsson N. Clinical electrophysiologic study of antiarrhythmic properties of flecainide: acute intraventricular delayed conduction and prolonged repolarization in regular paced and premature beats using intracardiac monophasic action potentials with programmed stimulation. Am Heart / 1981;102:864-871.

4. Hellestrand KJ, Bexton RS, Nathan AW, Spurrell RAJ, Camm AJ. Acute electrophysiological effects of flecainide acetate on cardiac conduction and refractoriness in man. Br Heart | 1982;48:140-148.

5. Anderson JL, Stewart JR, Perry BA, Van Hamersveld DD, Johnson TA, Conard GJ, Chang SF, Kvam DC, Pitt B. Oral flecainide acetate for the treatment of ventricular arrhythmias. $N$ Engl J Med 1981;305:473-477.

6. Duff H], Roden DM, Maffucci RJ, Vesper BS, Conard GI. Higgins SB, Oates JA, Smith RF, Woosley RL. Suppression of resistant ventriculur arrhythmius by twice daily dosing with flecainide. Am / Cardiol 1981;48:1133-1140.

7. Hodges M, Haugland JM, Granrud G, Conard GJ, Asinger RW, Mikell FL, Krejci J. Suppression of ventricular ectopic depolarizations by flecainide acetate, a new antiarrhythmic agent. Circulation 1982;65:879-885.

8. Somani P. Antiarrhythmic effects of flecainide. Clin Pharmacol Ther 1980;27:464-470.

9. Vanhaleweyk G, Balakumaran $\mathrm{K}$, Lubsen I, ten Cate Fl, Jovanovic A, Hagemeijer F, Withagen A, Polak BCP, Roelandt J, Hugenholtz PG. Flecainide: one-year efficacy in patients with chronic ventricular arrhythmias. Eur Heart I 1984;5:814-823.

10. Flowers D, O'Gallagher D, Torres V, Miura D, Somberg JC. Flecainide: long-term treatment using a reduced dosing schedule. Am | Cardiol 1985; 55:79-83.

11. Neuss H, Buss J, Schlepper M, Berthold R, Mitrovic V, Krämer A, Musial W]. Effects of flecainide on electrophysiological properties of accessory pathways in the Wolff-Parkinson-White syndrome. Eur Heart I 1983;4: $347-353$,

12. Bexton RS, Hellestrand KJ, Nathan AW, Spurrell RAJ; Camm AJ. A comparison of the antiarrhythmic effects on $A V$ functional reentrant tachycardia of oral and intravenous flecainide acetate. Eur Heart I 1983;4:92102.

13. Legrand V, Vandormael M, Collignon P, Kulbertus H. Hemodynamic effects of a new antiarrhythmic agent, Flecainide $(R-818)$, in coronary heart disease. Am I Cardiol 1982;51;422-426.

14. Serruys PW, Vanhaleweyk G, Van den Braind M, Verdouw P, Lubsen J, Hugenholtz PG. The haemodynamic effect of intravenous flecuinide in patients with coronary artery disease. Br I Clin Pharmacol 1983;16:51-59.

15. Josephson MA, Ikeda N, Singh BN. Effects of flecainide on ventricular function: clinical and experimental correlations. Am / Cardiol 1984;53:95B$100 \dot{B}$.

16. Hodges M, Hoback J, Graham E, Erlien D, Asinger R, Mikell F. Cardiac function after oral dosing with flecainide acetate. Clin Pharmacol Ther 1981;29:251.

17. Brower RW, Ten Katen HJ, Meester GT. Direct method for determining 
regional myocardiul shortening after bypass surgery from radiopayue markers in men. Am I Cádiol 1978;41:1222-1229.

18. Serruys PW, Brower R, Ten Katen HJ, Bom AH, Hugenholtz PG. Regional wall motion fram radiopaque markers after intravenous and intracoronary injections of nifedipine. Circulation 1981;63:584-591.

19. Brower RW, Serruys PW, Bos E, Nauta J. Regional myocardial shortening in relation to graft reactive hyperemia and flow after coronary bypass surgery. I Thorac Cardiovasc Surg 1979;7:92-100.

20. Bos RI, Serruys PW, Brower RW ten Katen HI, Vanhaleweyk G, Hugenholtz PG. Effect of long-term oral nifedipine therapy on left ventricular regional wall function at rest and during supine bicycle exercise. Eur Heart 1 1985;6:349-357.
21. Jaski B, Serruys PW. Epicurdial wall motion and left ventricular function during transluminal angioplasty in man. JACC 1985;6:695-700.

22. Schulze RA, Strauss HW, Pitt B. Sudden death in the year following myocardial infarction. Relation to ventricular premature contraction in the late hospital phase and left ventricular ejection fraction. Am I Med 1977; 62:192-199.

23. Conard GJ, Jernberg M], Carlson GL, Ober RE. Metabolism of R-818, an antiarrhythmic candidate, in rats. Pharmacologist 1975;17:194.

24. Tjandramaga $T B$, Verbesselt $R$, van Hecken A, Mullie A de Schepper PI. Intravenous and oral flecainide kinetics: absolute bio-availability, effects of food, antacid (aluminium hydroxide) and multiple oral doses. Eur Heart I 1984:5:suppl B:134. 